\title{
Unique neural coding of crucial versus irrelevant plant odors in a hawkmoth
}

\author{
Sonja Bisch-Knaden*1, Michelle A. Rafter ${ }^{2}$, Markus Knaden ${ }^{1}$, Bill S. Hansson ${ }^{1}$ \\ ${ }^{1}$ Max-Planck-Institute for Chemical Ecology, Dept. Evolutionary Neuroethology, Jena, \\ Germany \\ ${ }^{2}$ CSIRO Health \& Biosecurity, Dutton Park Queensland, Australia \\ *Corresponding author. Email: sbisch-knaden@ice.mpg.de
}

\begin{abstract}
The sense of smell is pivotal for nocturnal moths to locate feeding and oviposition sites. However, these crucial resources are often rare and their bouquets are intermingled with volatiles emanating from surrounding 'background' plants. Here we asked if the olfactory system of female hawkmoths, Manduca sexta, could differentiate between crucial and background cues. To answer this question, we collected nocturnal headspaces of numerous plants in a natural habitat of M. sexta. We analyzed the chemical composition of these headspaces, and used them as stimuli in physiological experiments at the antenna and in the brain. The intense odors of floral nectar sources evoked strong responses in virgin and mated female moths, most likely enabling the localization of profitable flowers at a distance. Bouquets of larval host plants and most background plants, in contrast, were subtle, thus potentially complicating host identification. However, despite being subtle, antennal responses and brain activation patterns evoked by the smell of larval host plants were clearly different from those evoked by other plants. Interestingly, this difference was even more pronounced in the antennal lobe of mated females, revealing a status-dependent tuning of their olfactory system towards oviposition sites. Our study suggests that female moths possess unique neural coding strategies to find not only conspicuous floral cues but also inconspicuous bouquets of larval host plants within a complex olfactory landscape.
\end{abstract}

\section{Introduction}

Nocturnal insects largely rely on their sense of smell to locate food sources and oviposition sites. However, preferred nectar sources or suitable host plants are often rare, and odors emitted by these essential plants are mixed with bouquets released by neighboring plants (Bruce, Wadhams, \& Woodcock, 2005). Plants that depend on nocturnal pollination, for example by hawkmoths, advertise their nectar-providing flowers with bright colors, and most notably by a strong scent to attract their nectar-feeding pollinators (Raguso, Henzel, Buchmann, \& Nabhan, 2003). Evolution has thus formed a system that greatly facilitates the location of nectar sources by foraging insects. The situation is very different when gravid females search for a suitable host plant for oviposition. Vegetative parts of plants, probably to remain cryptic to herbivores, emit only trace quantities of volatiles that might be difficult to identify against the olfactory background provided by other plants (Turlings et al., 1995). At the same time, leaf damage by insect herbivores leads to an increased emission of volatiles, sometimes attracting parasitoids and predators of these insects (Paré \& Tumlinson, 1999). Herbivore-induced plant volatiles are often similar across plant species (Mumm \& Dicke, 2010), and herbivores are omnipresent in natural environments. Together, these facts suggest that female moths searching for an oviposition site encounter either undamaged, olfactorily unremarkable plants or damaged plants with a more conspicuous volatile profile, components of which are shared across many nonhost plants. In any case, gravid moths have to identify suitable host plants against a vast odor scenery provided by the background vegetation. For this purpose, insects might depend on taxon-specific volatiles released by host plants but not by surrounding plants. An example is the cabbage moth Plutella xylostella that uses host-plant specific isothiocyanates to locate cruciferous hosts (Liu et al., 2020). Most insects, however, seem to identify host plants by 
blends of ubiquitous components that are present in plant-specific ratios. This has been shown in experiments, where small changes in the composition and ratios of crucial odor blends had a huge impact on the behavior of insects (Cha et al., 2008; Karpati, Knaden, Reinecke, \& Hansson, 2013; Visser \& Ave, 1978; Webster, Bruce, Pickett, \& Hardie, 2010). Furthermore, the chemical composition of crucial blends and the capability of the insect's antenna to detect specific components of these blends have been studied in detail (Conchou, Anderson, \& Birgersson, 2017; Fraser, Mechaber, \& Hildebrand, 2003; Tasin et al., 2010). In addition, neural activation patterns in the antennal lobe, the first olfactory processing center of the insect brain, upon stimulation with natural odor blends were investigated in different insect species (Burger et al., 2021; Lahondere et al., 2020; Saveer et al., 2012; Schubert, Hansson, \& Sachse, 2014). Usually, only odor blends that are known to be essential in the ecology of the insect were tested, as the aim of those studies was to reveal how crucial blends are coded in the brain.

However, it remains unclear how the olfactory systems of insects can differentiate between crucial and irrelevant blends, i.e., how peripheral detection and central representation allow the identification of food sources and oviposition sites within a complex olfactory environment. In our study, we collected headspaces of focal plants and background vegetation in the habitat of the tobacco hawkmoth Manduca sexta in Southern Arizona. Volatiles of hawkmoth-visited plants, like of most vegetation, differ between day and night both regarding floral (Hoballah et al., 2005; Raguso, Levin, Foose, Holmberg, \& McDade, 2003) and leaf emissions (De Moraes, Mescher, \& Tumlinson, 2001). We collected plant headspace only during the night, as we were interested in how the nocturnal $M$. sexta would detect and process these olfactory cues.

The primary nectar sources for M. sexta in the Southwestern United States are flowers of Agave palmeri and Datura wrightii. Pollen of these two species account for $90 \%$ of the pollen load on the proboscis of $M$. sexta (Alarcon, Davidowitz, \& Bronstein, 2008), a measurement that can be used as a proxy for flower visitation. Presence of pollen from Mirabilis longiflora and Mimosa dysocarpa on the moth's proboscis and nighttime observations reveal that these plants are additional secondary nectar sources in the same habitat (Alarcon et al., 2008; Grant \& Grant, 1983). Datura in addition to being a valuable nectar source for $M$. sexta is one of its two larval host plants in the area. Datura plants thus have to interact with an insect that is at the same time an important pollinator and a damaging herbivore. The other local host plant of M. sexta larvae is Proboscidea spp, the only known host belonging to a non-solanaceous family (Mechaber \& Hildebrand, 2000). Flowers of Proboscidea, however, are not visited by foraging hawkmoths, i.e. Proboscidea plants are suffering from leaf consumption by $M$. sexta larvae but do not profit from pollination by ovipositing moths. Furthermore, we sampled odors from another eleven native, frequent plants in the direct neighborhood of $M$. sexta's focal plants. These background plants have no documented relevance for $M$. sexta; they included flowering herbaceous plants, non-flowering woody shrubs or trees and tufts of grass. Three of the background plants, the desert willow Chilopsis linearis, the sunflower Helianthus annuus, and the wild grape Vitis arizonica, are larval hosts of other sympatric hawkmoth species (Table 1).

After collecting all nocturnal plant headspaces in situ in the field, we proceeded to analyze this comprehensive chemical database. We then used the plants' headspaces as stimuli in physiological experiments with female $M$. sexta. Specifically, we investigated which components of the volatile blends the moth's antenna can detect, and how the glomerular array of the antennal lobe is coding these complex odor bouquets. An insect's reaction to olfactory cues is known to be plastic in relation to its physiological condition. For example M. sexta has been demonstrated to differentially respond to plant odors depending on its age and mating status (Mechaber, Capaldo, \& Hildebrand, 2002). Underlying this differential response is a state-dependent modulation of the olfactory system, which may take place at the level of the antenna, the brain or at both levels (Gadenne, Barrozo, \& Anton, 2016; Saveer et al., 2012). Therefore, we investigated the peripheral detection of plant headspace and the central representation of this olfactory information in both virgin and mated $M$. sexta females. 
Our results revealed that the olfactory system of female moths responds strongly to odors related to nectar sources. Suitable oviposition substrates elicited much weaker but specific responses, a specificity that was most pronounced in gravid females. Evolution thus seems to have shaped an olfactory system that allows efficient feeding at all stages and that enables the mated female to pinpoint an optimal home for her offspring.

Table 1. Headspace collections from plants at the Santa Rita Experimental Range in Arizona (US).

\begin{tabular}{|c|c|c|c|c|c|c|}
\hline $\begin{array}{l}\text { Plant species (plant family), common } \\
\text { name }\end{array}$ & \multicolumn{2}{|c|}{ Type of sample } & $\begin{array}{l}\text { Nectar } \\
\text { source } \\
\text { for adult } \\
\text { M. sexta }\end{array}$ & $\begin{array}{l}\text { Host } \\
\text { plant for } \\
M . \text { sexta } \\
\text { larvae }\end{array}$ & $\begin{array}{l}\text { Larval host } \\
\text { plant for } \\
\text { sympatric } \\
\text { hawkmoths }\end{array}$ & $\begin{array}{l}\text { Nocturnal } \\
\text { pollination }\end{array}$ \\
\hline $\begin{array}{l}\text { Agave palmeri (Asparagaceae), } \\
\text { Palmer's century plant }\end{array}$ & \multicolumn{2}{|c|}{ Flower } & $X$ & - & - & $X$ \\
\hline $\begin{array}{l}\text { Datura wrightii (Solanaceae), Sacred } \\
\text { datura }\end{array}$ & Flower & Branch & $X$ & $X$ & $X^{*}$ & $\mathrm{X}$ \\
\hline $\begin{array}{l}\text { Mimosa dysocarpa (Fabaceae), } \\
\text { Velvetpod }\end{array}$ & \multicolumn{2}{|c|}{ Flowering branch } & $X$ & - & - & $\mathrm{X}$ \\
\hline $\begin{array}{l}\text { Mirabilis longiflora (Nyctaginaceae), } \\
\text { Sweet four o'clock }\end{array}$ & \multicolumn{2}{|c|}{ Flowering branch } & $\mathrm{X}$ & - & - & $X$ \\
\hline $\begin{array}{l}\text { Proboscidea parviflora } \\
\text { (Martyniaceae), Devil's claw }\end{array}$ & \multicolumn{2}{|c|}{ Flowering plant } & - & $X$ & - & - \\
\hline $\begin{array}{l}\text { Chilopsis linearis (Bignoniaceae), } \\
\text { Desert willow }\end{array}$ & \multicolumn{2}{|c|}{ Branch with seeds } & - & - & $\mathrm{X}^{* *}$ & - \\
\hline $\begin{array}{l}\text { Helianthus annuus (Asteraceae), } \\
\text { Common sunflower }\end{array}$ & \multicolumn{2}{|c|}{ Flowering plant } & - & - & $\mathrm{X}^{* * *)}$ & $X$ \\
\hline Vitis arizonica (Vitaceae), Wild grape & \multicolumn{2}{|c|}{ Branch } & - & - & $\mathrm{X}^{* * * * *}$ & - \\
\hline $\begin{array}{l}\text { Amaranthus palmeri (Amaranthaceae), } \\
\text { Carelessweed }\end{array}$ & \multicolumn{2}{|c|}{ Flowering plant } & - & - & - & - \\
\hline $\begin{array}{l}\text { Argemone pleiacantha (Papaveraceae), } \\
\text { Prickly poppy }\end{array}$ & \multicolumn{2}{|c|}{ Flowering branch } & - & - & - & - \\
\hline $\begin{array}{l}\text { Baccharis salicifolia (Asteraceae), } \\
\text { Seepwillow }\end{array}$ & \multicolumn{2}{|c|}{ Branch with buds } & - & - & - & - \\
\hline $\begin{array}{l}\text { Gutierrezia sarothrae (Asteraceae), } \\
\text { Snakeweed }\end{array}$ & \multicolumn{2}{|c|}{ Flowering plant } & - & - & - & - \\
\hline Poaceae spp,, Grass & \multicolumn{2}{|c|}{ Tuft of grass } & - & - & - & - \\
\hline $\begin{array}{l}\text { Prosopis velutina (Fabaceae), Velvet } \\
\text { mesquite }\end{array}$ & \multicolumn{2}{|c|}{ Branch } & - & - & - & - \\
\hline $\begin{array}{l}\text { Quercus emoryi (Fagaceae), Emory } \\
\text { oak }\end{array}$ & \multicolumn{2}{|c|}{ Branch } & - & - & - & - \\
\hline $\begin{array}{l}\text { Senna hirsuta v glaberrima } \\
\text { (Fabaceae), Woolly Senna }\end{array}$ & \multicolumn{2}{|c|}{ Flowering plant } & - & - & - & - \\
\hline
\end{tabular}

\section{Results}

116 Nocturnal emissions of plants in the habitat of $M$. sexta

117 We collected the nocturnal headspaces of 17 plant species at the Santa Rita Experimental Range, our study site in southern Arizona (Fig. 1A, Table 1). Headspace samples were analyzed chemically by gas chromatography coupled with mass spectrometry (GC-MS). We first evaluated the number of GC-peaks per sample as a proxy for the number of volatile compounds present. In ten of the 17 plant samples, the number of emitted compounds was in the range of blank control collections (Fig. 1B, grey area). The richest volatile bouquets, on the other hand, were emitted by the sunflower Helianthus, and by M. sexta's nectar sources Datura flower, Agave flower, and Mirabilis. When we considered not only the number of GC-peaks but also their chemical identity, the same four bouquets revealed distinct chemical profiles. Headspaces of the remaining plants were statistically distinctive but largely overlapping due to low emission rates, and shared volatiles, which were also present in the blank control samples (Fig. 1C; oneway ANOSIM, $\mathrm{R}=0.67, \mathrm{p}<0.0001$; Bray-Curtis similarity index). 
bioRxiv preprint doi: https://doi.org/10.1101/2022.02.08.479530; this version posted February 10,2022 . The copyright holder for this preprint (which was not certified by peer review) is the author/funder, who has granted bioRxiv a license to display the preprint in perpetuity. It is made available under aCC-BY 4.0 International license.

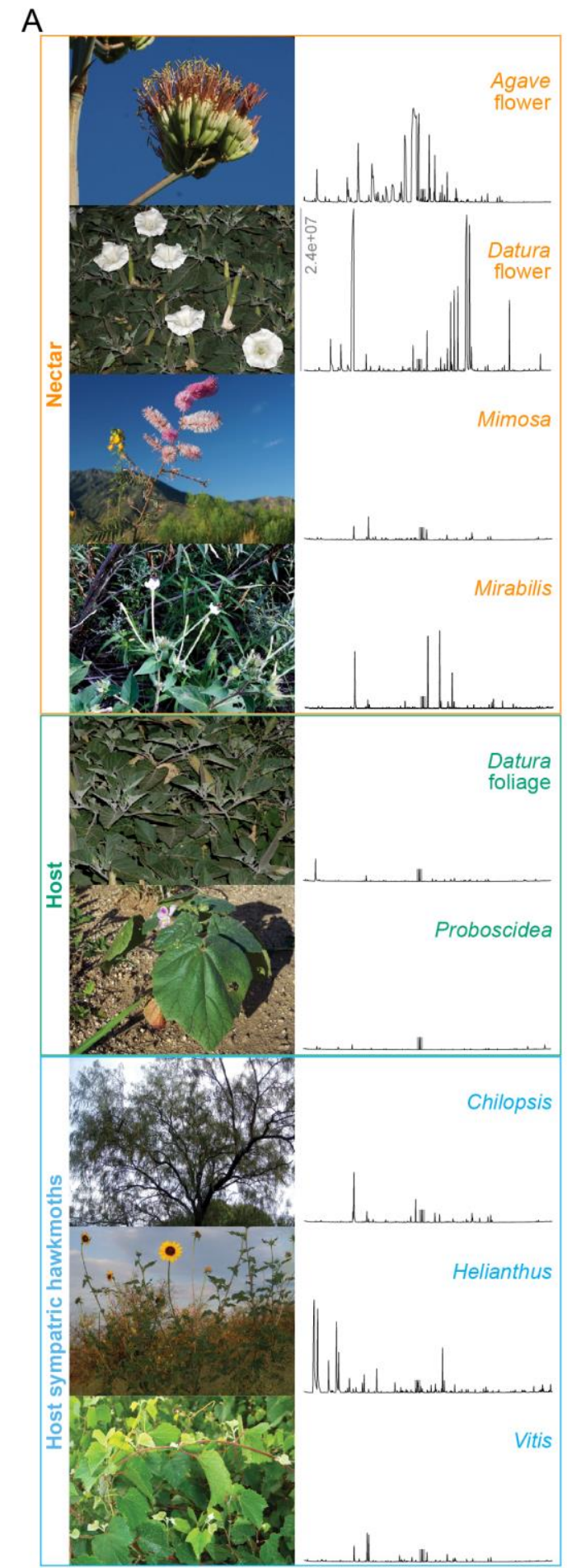

B
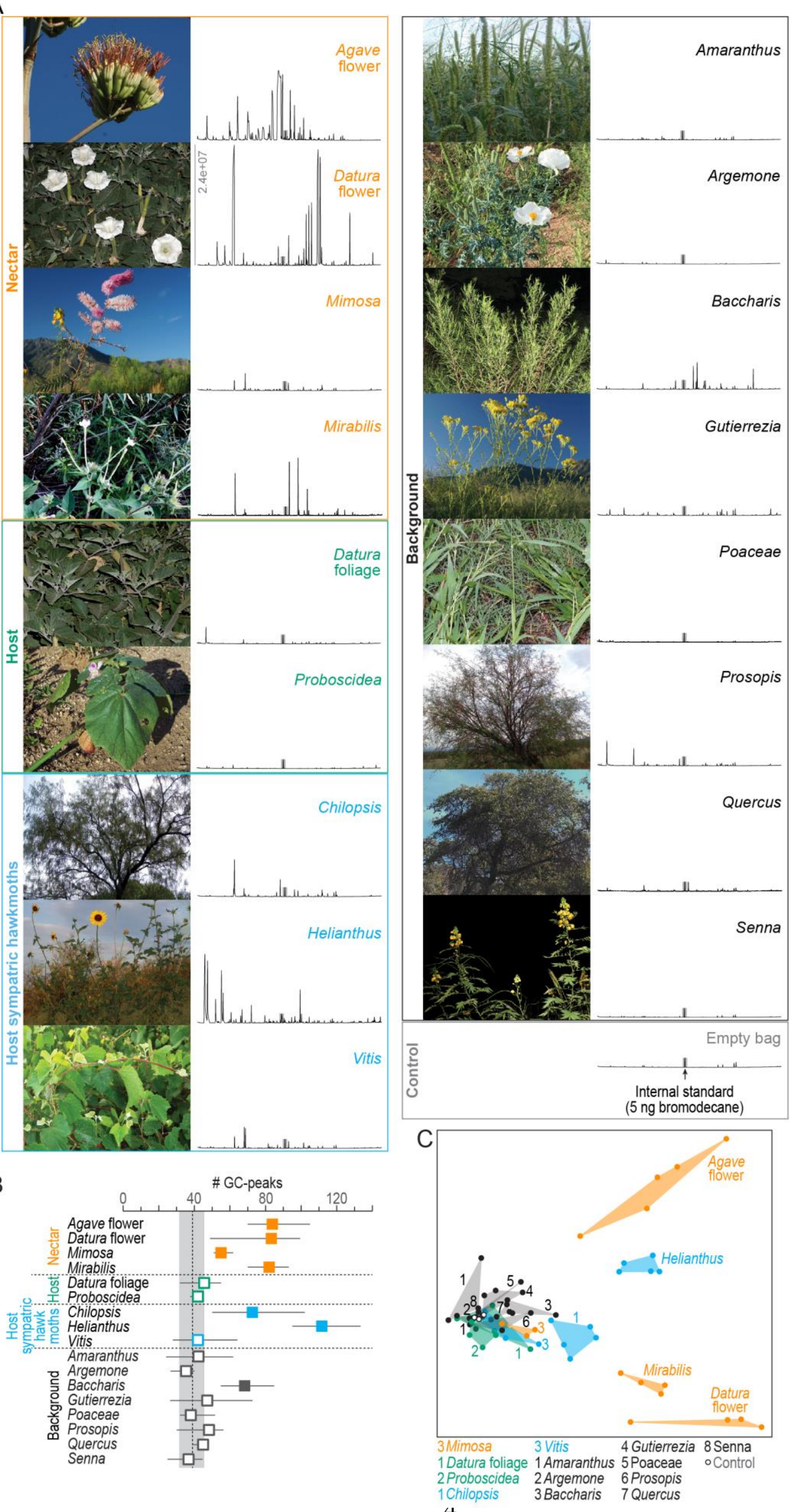

4 
Fig. 1. Chemical analysis of nocturnal headspaces collected from plants in the habitat of $M$. sexta in southern Arizona.

(A) Representative photographs (left) and chromatographs (right) of each headspace collection. $X$-axis of chromatographs; retention time, $y$-axis, abundance, same scale for all headspaces, maximum abundance indicated in Datura flower headspace; grey bar, internal standard (5 ng 1-bromodecane).

(B) Number of GC-peaks. Squares, average values of 3-5 individual plant samples; whiskers, range; dotted line and grey area, average and range of control values obtained from nocturnal collections in the same habitat with empty bags $(n=2)$, and with unused filter material $(n=1)$; open squares, within control range, filled squares, outside control range.

(C) Non-metric multidimensional scaling plot (Bray-Curtis, 2D stress: 0.09) based on a nontargeted analysis (https://xcmsonline.scripps.edu (Tautenhahn, Patti, Rinehart, \& Siuzdak, 2012)) of 69 chromatograms (Source data S1). Color code of plant samples as in B.

\section{What does the moth detect?}

So far, our analysis considered the chemistry of nocturnal plant emissions. However, M. sexta might still be able to detect plant volatiles occurring only in trace amounts but having a high biological significance, e.g. to identify an appropriate oviposition site. Therefore, we performed GC-coupled electro-antennographic detection (GC-EAD) using the antennae of female M. sexta as biological detectors. This technique allows successive presentation of headspace compounds in naturally occurring concentrations to the moth antenna and, in parallel, recording of the pooled response of all antennal olfactory sensory neurons (Fig. 2A). We first evaluated the number of EAD-active fractions in the effluent of the GC for each sample type (Fig. 2B). With the exception of two background plants (Argemone, Gutierrezia), all plant bouquets contained EAD-active fractions. The nectar sources Agave flower and Datura flower emitted the highest number of compounds (on average 20 and 17 active fractions, respectively), followed by the bouquets of host plants of sympatric hawkmoths (Chilopsis, Helianthus, Vitis) and a background tree (Prosopis) (11-14 active fractions). The two larval host plants of M. sexta, on the other hand, contained only 4-7 active compounds.

Across all headspaces, we found 77 EAD-active compounds (Fig. 2C) and could tentatively identify 69 of them. These compounds mainly belonged to three chemical classes: terpenes, aliphatic esters, and aromatics. The most potent antennal stimulants $(n=16)$ elicited median EAD amplitudes $>1.0 \mathrm{mV}$. Eight of these strongly activating odors were aliphatic esters present exclusively in the bouquet of Agave flowers; three more odors were present in the headspace of nectar sources (Agave flower, Datura flower, and/or Mirabilis) but not in other sample types. The remaining strongly activating odors each occurred in at least five plant species from all sample types and included the most common volatiles in our collections: (Z)-3-hexenyl acetate (11 plants) and beta-ocimene (10 plants). When we plotted the concentration of the most activating GC-fractions versus the EAD amplitude they evoked, we found that alpha-copaene, (Z)-3-hexenyl acetate, and beta-ocimene were the most active odors at concentrations below 5 ng in 12 hours of odor collection (Fig. 2D).

The antenna of $M$. sexta was in addition reacting with a weaker response towards many more plant-released volatiles in a species-specific manner. Furthermore, two-thirds of all EAD-active GC-fractions (51 out of 77) were restricted to one of the plant species (Fig. 2C). Thus, beyond the impression received from the chemical analysis (Fig. 1C), the moths' antennae seemed to be well suited to distinguish between plant bouquets even when they had low volatile concentrations and inconspicuous chemical profiles, like the two larval host plants of M. sexta and most background plants. The mating status of the moth had no impact on its detection capabilities at the level of the antenna (two-way ANOSIM, mating status: $\mathrm{R}=-0.06, \mathrm{p}=0.756$, plant species: $\mathrm{R}=0.97, \mathrm{p}<0.0001$; Bray-Curtis similarity index). 

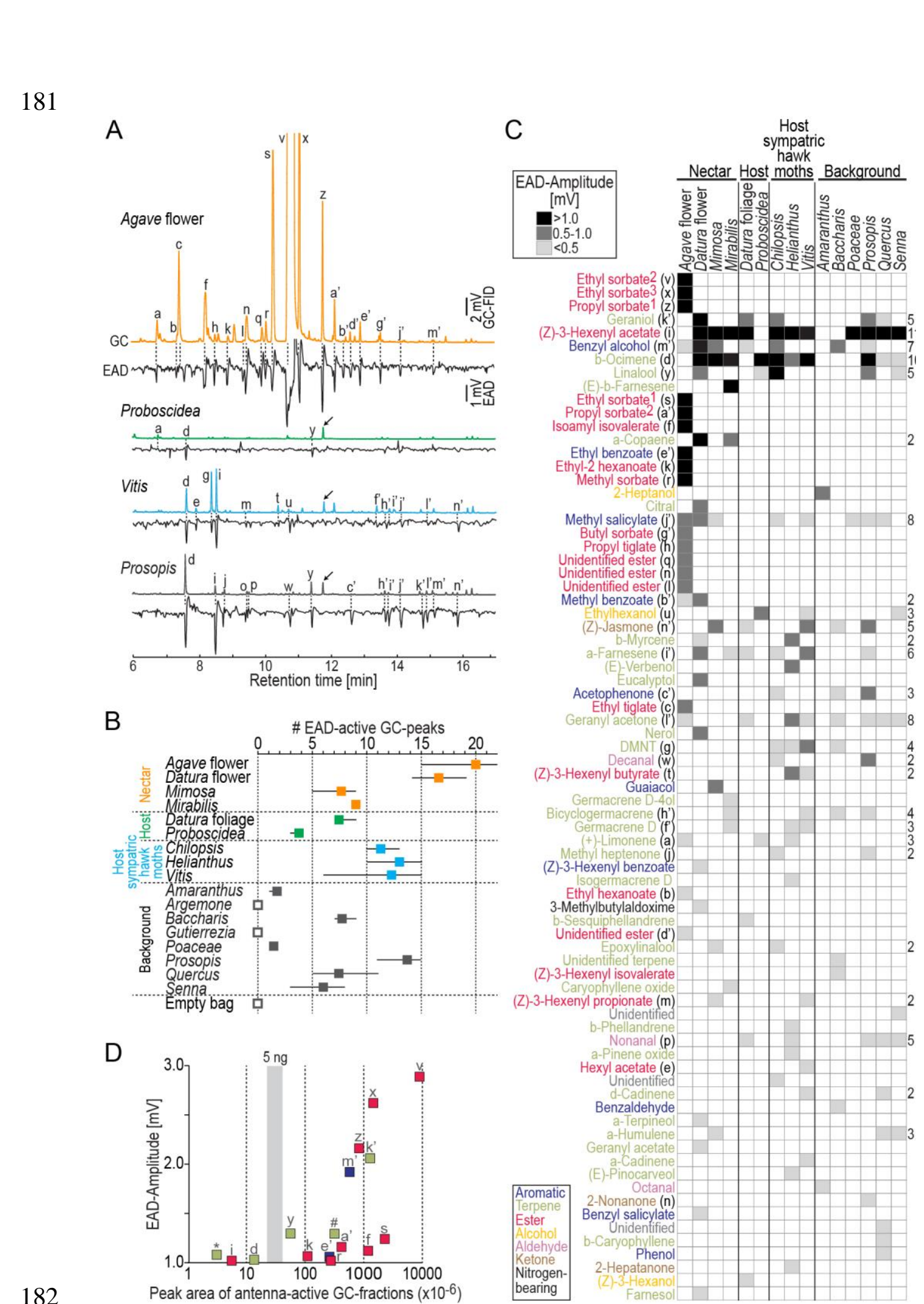

Fig. 2. Antennal responses of $M$. sexta females to nocturnal headspaces of plants.

(A) Examples of GC-EAD recordings after stimulation with four plant headspaces representing nectar sources (Agave flower), host plants (Proboscidea), host plants of sympatric hawkmoths (Vitis), and background plants (Prosopis). Upper traces, gas chromatograph-coupled flame ionization detection (GC-FID), lower traces electro-antennographic detection (EAD) of female M. sexta. Letters indicate EAD-active GC-peaks (labelled in C) that evoked a response in at least three animals. Arrows, internal standard: $5 \mathrm{ng}$ 1-bromodecane; in Agave flower, the internal standard co-eluted with GC-peak ' $\mathrm{z}$ ', and GC-peaks ' $\mathrm{v}$ ' and ' $\mathrm{x}$ ' are cropped. 
(B) Number of EAD-active GC-peaks per plant species. We stimulated the antennae (4-7 moths/headspace) with the same representative sample per headspace type. Filled squares, average values; whiskers, range; open squares, no active GC-peaks detected in three moths. Each moth was tested only once. (C) Antennal responses towards GC-peaks (rows) present in headspace (columns). Each cell in the heat map represents the median EAD amplitude of on average five moths (range: 4-7) per headspace. Rows are sorted by EAD-amplitude (Source data S2); magnitude of response is coded by shades of gray (see inset at top), empty cells, no response/GC-fraction not present. Color-code of compounds according to chemical class (see inset at bottom). Numbers next to ethyl sorbate and propyl sorbate label different enantiomers present in Agave flower, and depict their order by retention time; $D M N T$, (E)-4,8-dimethyl-1,4,7-nonatriene. Numbers to the right of the heat map depict how often a given compound was present; rows without numbers indicate compounds found only in one headspace.

(D) Effectiveness of the strongest antennal stimulants. $X$-axis, concentration of compounds derived from their peak area (logarithmic scale); $y$-axis, median EAD-amplitudes $\geq 1 \mathrm{mV} ;$ grey vertical bar, range of peak areas of the internal standard 1-bromodecane (5 ng). For compounds present in more than one plant species, the lowest concentration eliciting a median EAD amplitude $\geq 1 \mathrm{mV}$ was chosen; letters indicate compounds as in C; *, alpha-copaene, \#, (E)beta-farnesene. Peak area of ethyl sorbate ${ }^{2}$ ('v') shows lower limit of concentration as the GC seemed overloaded with this odor.

\section{How is plant headspace represented in the moth's antennal lobe?}

In in vivo calcium imaging experiments, we successively stimulated the antennae of female $M$. sexta with puffs of the plant bouquets collected in Arizona and recorded the odor-evoked neural activity among the olfactory glomeruli of their antennal lobe. Olfactory glomeruli are functional subunits occurring in species-specific numbers. Female $M$. sexta possess 70 glomeruli arranged in a monolayer around a central neuropil (Grosse-Wilde et al., 2011). Activity patterns of glomeruli in the dorsal-frontal part of the antennal lobe can be monitored using in vivo calcium imaging (Hansson, Carlsson, \& Kalinova, 2003; Sachse, Rappert, \& Galizia, 1999). To enable comparison of headspace-evoked activation patterns among different animals, we identified 23 glomeruli in each moth using diagnostic, monomolecular odorants (Fig. 3A and B, (BischKnaden, Dahake, Sachse, Knaden, \& Hansson, 2018)). We found that plant headspace activated these 23 identified glomeruli (Fig. 3C). However, two glomeruli (22 and 23) responded exceptionally weak. They are tuned to acids and amines (Bisch-Knaden et al., 2018), chemical classes that were functionally absent in the tested plant bouquets (Fig. 2C). Next, we tested which responses were true headspace-evoked responses, i.e. which responses were different from the response towards stimulations with the eluent dichloromethane (Fig. 3D), and normalized the fluorescent signals of headspace-evoked responses for each glomerulus and animal (Fig. 3E).

Consistent with the results from GC-EAD experiments, Datura and Agave bouquets were again unique regarding not only the number of activated glomeruli (Fig. 3D) but also the strength of response (Fig. 3E). Datura flower scent evoked the maximal response recorded in all but two glomeruli in virgin females (glomeruli 12 and 21), and in all but one glomerulus in mated females (glomerulus 12). Agave flower scent was the best activator for these remaining glomeruli. Apart from the weak activation levels of glomeruli 22 and 23, this exceptional representation of $M$. sexta's two primary nectar sources was independent of the females' mating status (Table 2).

Volatiles emitted by $M$. sexta's larval host plants each activated only a single glomerulus in the antennal lobe of females. Glomerulus 4 responded to the bouquet of Datura foliage irrespective of the female's mating status; Proboscidea headspace, however, activated a different single 
243 glomerulus in virgin (glomerulus 15) than in mated females (glomerulus 12). Furthermore, we 244 observed a notable effect of the mating status on the representation of plants that are oviposition 245 sites of sympatric hawkmoths (Chilopsis, Helianthus, Vitis). These plants evoked a major 246 response in the antennal lobe of virgin $M$. sexta females (8-13 activated glomeruli), and an even 247 stronger response in mated females (11-16 activated glomeruli). In contrast, females became 248 almost anosmic towards the headspace of background plants following mating, as these plants 249 activated on average 3.1 glomeruli (range: $0-9$ ) in virgin, but only 0.6 glomeruli (range: $0-2$ ) in 250 mated females. The few glomeruli still responding towards background bouquets were different 251 from the two host plant-activated glomeruli.

252 A multivariate analysis confirmed that mating status as well as plant species had a significant 253 effect on overall activation patterns across glomeruli in the antennal lobe (two-way ANOSIM, 254 mating status: $\mathrm{R}=0.71, \mathrm{p}=0.0001$, plant species: $\mathrm{R}=0.83, \mathrm{p}=0.0001$; Bray-Curtis similarity 255 index). 

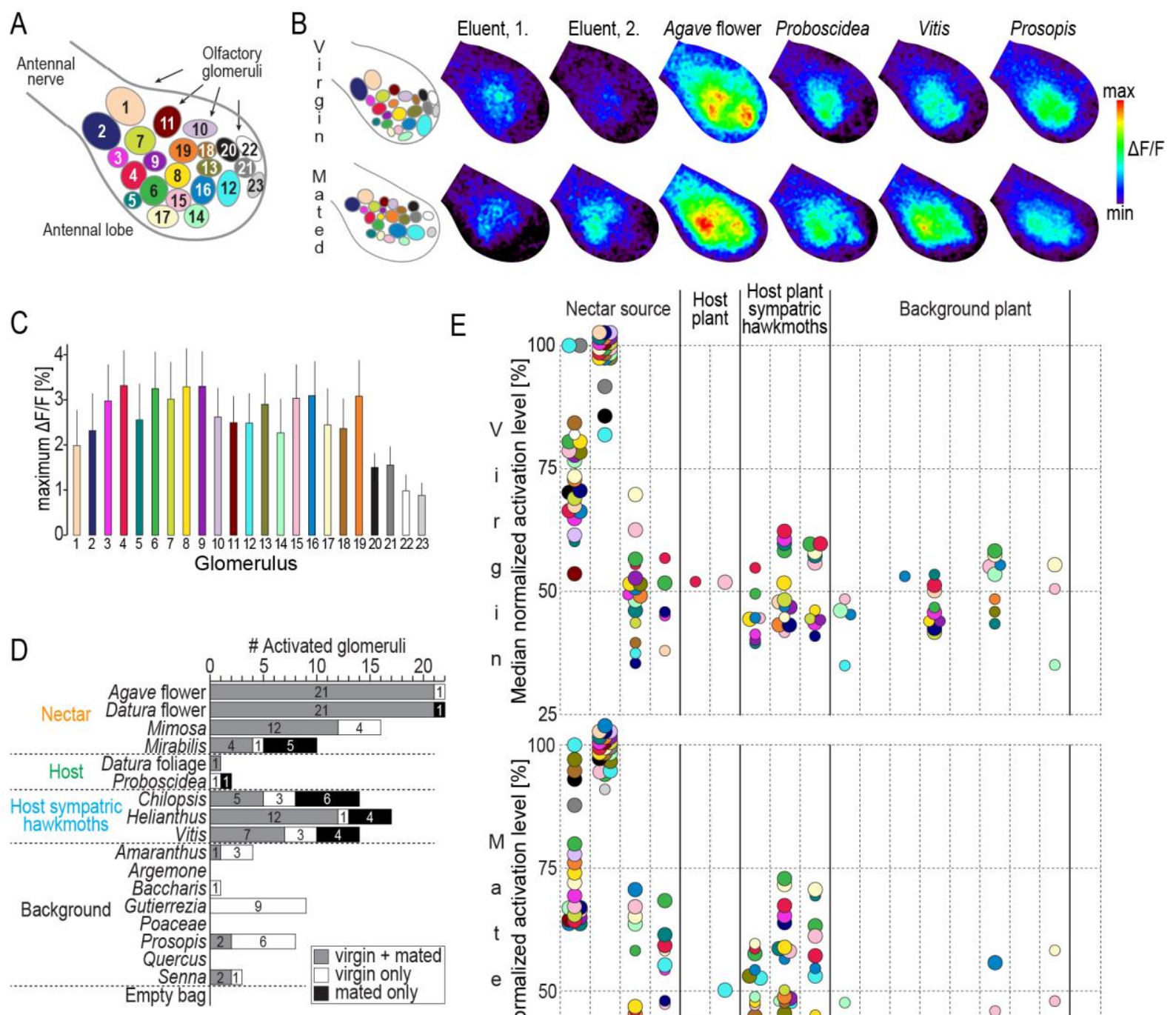

Fig. 3. Headspace-evoked activity patterns in the antennal lobe of female M. sexta.

(A) Schematic of 23 olfactory glomeruli at the dorsal surface of the right antennal lobe. Entrance of the antennal nerve is in the upper left corner. Numbers, glomeruli identification as in (Bisch-Knaden et al., 2018).

265 (B) Examples of in vivo calcium imaging recordings after stimulation with the eluent dichloromethane (first and second stimulation at the beginning and at the end of the experiment) and four plant headspaces representing nectar sources (Agave flower), host plants (Proboscidea), host plants of sympatric hawkmoths (Vitis), and background plants (Prosopis). Left column, schematic of individual antennal lobes, colors as in A. Right columns, false-colorcoded imaging results of the right antennal lobe in a virgin female (top row), and a mated female (bottom row), normalized to their highest response (see color bar).

(C) Maximum increase of fluorescence in 23 identified glomeruli. Graph depict for each glomerulus (color code as in A) the average maximum responses (bars) and one standard deviation (whiskers) of 10 virgin and 10 mated females after stimulation with plant headspaces. (D) Number of activated glomeruli in the antennal lobe depending on female mating status. A glomerulus was scored as activated if its headspace-evoked response was different from the 
averaged response to the two stimulations with the eluent dichloromethane ( $p<0.01$, Friedman test with Dunn's multiple comparisons test). For the identity of glomeruli activated by each plant headspace, see Table 2. (E) Activity levels evoked by plant headspace in individual glomeruli in the antennal lobe. Colored dots represent median normalized responses of activated glomeruli in 10 virgin (top) and 10 mated (bottom) females; color-code of glomeruli as in A. Only values of activated glomeruli are shown (small circles, $\mathrm{p}<0.01$, large circles, $\mathrm{p}<0.001$, Friedman test with Dunn's multiple comparisons test, Source data S3).

Table 2. Headspace-activated glomeruli independent and dependent of mating status.

\begin{tabular}{|c|c|c|c|}
\hline Glomerulus & $\begin{array}{l}\text { Response independent of } \\
\text { mating status }\end{array}$ & Response only before mating & Response only after mating \\
\hline $1^{*}$ & Agave, Datura & $\begin{array}{l}\text { Mirabilis, Helianthus, } \\
\text { Gutierrezia }\end{array}$ & \\
\hline 2 & $\begin{array}{l}\text { Agave, Datura, Mirabilis, } \\
\text { Helianthus }\end{array}$ & Mimosa, Vitis, Gutierrezia & \\
\hline 3 & $\begin{array}{l}\text { Agave, Datura, Mirabilis, } \\
\text { Helianthus }\end{array}$ & $\begin{array}{l}\text { Mimosa, Chilopsis, Vitis, } \\
\text { Gutierrezia }\end{array}$ & \\
\hline $4^{*}$ & $\begin{array}{l}\text { Agave, Datura, Mimosa, } \\
\text { Mirabilis, Datura foliage, } \\
\text { Chilopsis, Helianthus, Vitis }\end{array}$ & Gutierrezia & \\
\hline 5 & $\begin{array}{l}\text { Agave, Datura, Helianthus, } \\
\text { Vitis }\end{array}$ & $\begin{array}{l}\text { Mimosa, Chilopsis, } \\
\text { Gutierrezia, Prosopis }\end{array}$ & Mirabilis \\
\hline $6^{*}$ & $\begin{array}{l}\text { Agave, Datura, Mimosa, } \\
\text { Mirabilis, Chilopsis, } \\
\text { Helianthus, Vitis }\end{array}$ & Gutierrezia, Prosopis & \\
\hline 7 & Agave, Datura, Helianthus & Mimosa, Vitis, Gutierrezia & \\
\hline 8 & $\begin{array}{l}\text { Agave, Datura, Mimosa, } \\
\text { Chilopsis, Helianthus, Vitis }\end{array}$ & Gutierrezia & \\
\hline 9 & $\begin{array}{l}\text { Agave, Datura, Mimosa, } \\
\text { Helianthus, Vitis }\end{array}$ & Chilopsis, Gutierrezia & \\
\hline 10 & Agave, Datura & & \\
\hline 11 & Agave, Datura & & \\
\hline $12^{*}$ & Agave, Datura, Mimosa & Amaranthus & $\begin{array}{l}\text { Mirabilis, Proboscidea, } \\
\text { Chilopsis, Helianthus, Vitis }\end{array}$ \\
\hline $13^{*}$ & Agave, Datura, Mimosa & Prosopis & $\begin{array}{l}\text { Mirabilis, Chilopsis, } \\
\text { Helianthus, Vitis }\end{array}$ \\
\hline 14 & $\begin{array}{l}\text { Agave, Datura, Mimosa, } \\
\text { Amaranthus }\end{array}$ & Prosopis, Senna & Chilopsis, Helianthus \\
\hline 15 & $\begin{array}{l}\text { Agave, Datura, Mimosa, } \\
\text { Chilopsis, Helianthus, Vitis, } \\
\text { Prosopis, Senna }\end{array}$ & Proboscidea, Amaranthus & Mirabilis \\
\hline 16 & $\begin{array}{l}\text { Agave, Datura, Mimosa, } \\
\text { Chilopsis, Helianthus, Prosopis }\end{array}$ & Amaranthus, Baccharis & Vitis \\
\hline $17^{*}$ & $\begin{array}{l}\text { Agave, Datura, Mimosa, } \\
\text { Helianthus, Vitis, Senna }\end{array}$ & Prosopis & Mirabilis, Chilopsis \\
\hline $18^{*}$ & Agave, Datura, Mimosa & & Chilopsis, Helianthus \\
\hline $19^{*}$ & $\begin{array}{l}\text { Agave, Datura, Mimosa, } \\
\text { Helianthus }\end{array}$ & Prosopis & Chilopsis, Vitis \\
\hline $20^{*}$ & Agave, Datura & & \\
\hline $21^{*}$ & Agave, Datura & & \\
\hline 22 & & Agave & \\
\hline 23 & & & Datura \\
\hline
\end{tabular}

Font colors: orange, nectar source of M. sexta, green, host plant of M. sexta; blue, host plant of sympatric hawk moths; black, background plant.

290 *Glomerulus whose activation level is positively correlated with odor-guided behavior of virgin females in wind tunnel experiments (Bisch-Knaden et al., 2018). 


\section{Discussion}

For a female moth, two plant-based resources are of overriding importance: flowers providing nectar for sustenance of the animal itself and plants providing suitable oviposition sites and thereby food for the offspring. Here, we studied how the olfactory system of the female hawkmoth, $M$. sexta, has evolved to allow unambiguous identification of these resources based on their emissions of volatile molecules.

As could be expected, plants that predominately (Datura, Mirabilis) or at least partly (Agave) rely on nocturnal pollination by hawkmoths (Alarcon et al., 2008; Emiliano Trejo-Salazar, Scheinvar, \& Eguiarte, 2015) sent a clear and distinctive chemical signal in the night. In addition, the sunflower Helianthus emitted a strong and distinct scent, illustrating that its around-the-clock open flowers depend not only on diurnal but also on nocturnal pollinators. Although M. sexta is not described as a pollinator of Helianthus (Torretta, Navarro, \& Medan, 2009), unspecified pollen from the sunflower family was found on the proboscis of M. sexta and other hawkmoths, indicating that these moths occasionally feed also on sunflowers (Alarcon et al., 2008). Low nighttime emissions observed in the remaining samples might reflect the plants' independence of nocturnal pollination (in the case of flowering plants), or an avoidance strategy against herbivory (for collections from non-flowering branches). When we tested the antenna of female $M$. sexta with plant headspaces using GC-EAD, we found that the moths' detection and discrimination capability appeared to be better than could be inferred from the chemical analysis, and was independent of the female's mating status. Olfactory coding at the level of the antenna indicates that the moths might not only be able to discriminate between strong and complex scents emitted by nectar sources but also between host plant bouquets and background plants. However, the highest number of active compounds was present in the floral headspace of Agave and Datura. Particularly, the bouquet of Agave contained nine of the 16 strongest antennal stimulants, eight of them being aliphatic esters. These esters are signature compounds of Agave flowers, as they are rarely found in other floral headspace investigated in almost 1000 plant species from 90 families (Knudsen, Eriksson, Gershenzon, \& Stahl, 2006). Particularly, this chemical class is lacking in typical hawkmothflowers (Raguso, Henzel, et al., 2003; Raguso, Levin, et al., 2003). Two enantiomers of the Agave-characteristic ester ethyl sorbate elicited the strongest antennal response of all active GC-peaks (median EAG-amplitudes: $2.6 \mathrm{mV}$ and $2.9 \mathrm{mV}$, stimulus concentrations: $\sim 0.5 \mu \mathrm{g}$ and $>0.5 \mu \mathrm{g}$, Fig. 2D). These responses are higher than the response of a male antenna when stimulated with bombykal, the main component of $M$. sexta's sex-pheromone ( $1.9 \mathrm{mV}$, stimulus concentration: $100 \mu \mathrm{g}$ (Fandino et al., 2019)). Even if we consider that bombykal has a lower vapor pressure than ethyl sorbate and that less odor might reach the antenna in EAG than in GC-EAD experiments, this comparison indicates that the female antenna is at least as excitable by promising floral, i.e. nectar-indicating volatiles, as the male antenna by the female sexpheromone.

EAD-activity might correlate with behavior (Liu et al., 2020; Zhu, Keaster, \& Gerhardt, 1993), but a strong antennal response towards an odor does not always imply a strong behavioral response to this odor molecule (Honda, Omura, \& Hayashi, 1998; Suckling, Karg, Gibb, \& Bradley, 1996). In M. sexta, a comparison of physiological and behavioral data is possible as almost half of the active and identified GC-peaks in our current study were previously tested in a wind tunnel assay (Bisch-Knaden et al., 2018). EAD amplitudes evoked by these 31 shared odors belonging to seven chemical classes are indeed positively correlated with the duration a female moth shows feeding behavior, i.e. contacts a scented filter paper with its proboscis (Pearson correlation coefficient $\mathrm{r}=0.41, \mathrm{p}=0.023$ ). In contrast, no correlation was found between EAD activity and the duration of abdomen curling behavior, i.e. behavior related to oviposition $(\mathrm{r}=-0.03, \mathrm{p}=0.9)$. Hence, no conclusions from GC-EAD results can be drawn regarding an odor's relevance in connection with an oviposition site, whereas odors that evoked a strong response at the antenna of female $M$. sexta often are attractive in the context of feeding. 
In previous GC-coupled single sensillum recordings (GC-SSR), 60\% of randomly chosen olfactory sensilla on the antenna of female $M$. sexta reacted to the aliphatic ester (Z)-3-hexenyl acetate when stimulated with the scent of herbivore-damaged Datura foliage (Spaethe, Reinecke, Olsson, et al., 2013). If the olfactory sensory neurons housed in these sensilla would not only detect (Z)-3-hexenyl acetate but aliphatic esters in general, this could explain the prominent response towards typical Agave esters in our GC-EAD experiments. In addition, the antenna might harbor narrowly tuned neurons, or rather olfactory receptors, strongly responding only to Agave esters. Hawkmoth-pollinated flowers like Datura, Nicotiana, and Petunia emit oxygenated aromatics that are especially attractive to foraging hawkmoths and elicit a strong response from the antenna of $M$. sexta, and in its antennal lobe, respectively (Bisch-Knaden et al., 2018; Hoballah et al., 2005; D. Kessler, Gase, \& Baldwin, 2008; Riffell, Lei, Abrell, \& Hildebrand, 2013). Our present study shows that M. sexta females in addition exhibit a robust physiological response towards the bouquet collected from Agave flowers, reflecting the significant role this copious nectar source - releasing a very different smell than typical hawkmoth-flowers - plays in $M$. sexta's foraging behavior. The moths tested in our study were laboratory-reared on artificial diet, naïve to plant odors, not fed, and tested only once. Hence, we consider our results to reflect innate and not learned responses. Other hawkmoth species feeding on nectar from Agave flowers might share similar olfactory detection and processing abilities (Alarcon et al., 2008; Emiliano Trejo-Salazar et al., 2015).

Three volatiles, alpha copaene, (Z)-3-hexenyl acetate and beta ocimene, stood out as particularly strong activators of the female $M$. sexta antenna although they were present in very low concentrations. The high sensitivity towards these odors might indicate that they act as long-distance cues guiding the moth to places with vegetation (Webster \& Carde, 2017). Furthermore, these odors have meanings that are more specific: alpha-copaene is involved in the oviposition decision process of $M$. sexta (Zhang et al., 2022) and in addition might indicate rewarding nectar sources as it was functionally present, i.e. EAD-active, only in the headspace of Datura flower and Mirabilis. (Z)-3-hexenyl acetate and beta ocimene, on the other hand, are typical herbivore-induced volatiles and are released by herbivore-damaged Datura leaves (Hare \& Sun, 2011). They might thus inform an $M$. sexta female searching for oviposition sites about the presence of potential larval competitors and predators already at a distance.

An earlier GC-EAD study with female $M$. sexta reported that Datura and Proboscidea foliage each emit ten identified EAD-active compounds, and share eight of them (Fraser et al., 2003). Our work, in contrast, shows that both host plants emit only nine and four active compounds, respectively, and have no active compounds in common. In the case of Proboscidea, none of the active GC-peaks was even overlapping between both studies. Many methodological factors could have contributed to this discrepancy in the results. In detail, Fraser et al. collected headspace from single, potted, undamaged plants with buds, flowers and seeds removed; and a cultivar of Proboscidea was used, not the wild type. In our study, we collected headspace of local, mostly herbivore-damaged plants growing in a natural plant community and we did not remove any parts of the plant. In addition, our odor collection lasted 12 hours during the natural dark phase versus 24 hours of artificially induced scotophase in (Fraser et al., 2003). Conditions like growth in mixed plant populations or in monocultures (Kigathi, Weisser, Reichelt, Gershenzon, \& Unsicker, 2019), light deprivation (He, Halitschke, Schuman, \& Baldwin, 2021), herbivore-attack and other stress factors (Holopainen \& Gershenzon, 2010) influence both composition and quantity of plant-emitted volatiles. Therefore, the observed differences between the studies could be expected and emphasize the significance of odor collections in the field.

Bath application of a fluorescent calcium-sensor allows monitoring of odor-induced neural activity in the brain. Each neuron type in the treated brain region might take up the marker molecules. However, as each glomerulus in the antennal lobe receives input from 4000-5000 olfactory sensory neurons (Oland \& Tolbert, 1988), and is targeted by only four to five 
projection, i.e. output neurons (Homberg, Montague, \& Hildebrand, 1988), odor-evoked activation patterns in calcium imaging experiments can be assumed to reflect mainly the activity of input neurons. Additionally, about 360 local interneurons per antennal lobe (Homberg et al., 1988) with inhibitory and/or excitatory functions (Reisenman, Dacks, \& Hildebrand, 2011) might synapse back onto the sensory neurons, thus modulating their activity and accordingly the observed calcium signal. Although most of these interneurons arborize in many, if not all glomeruli, some interneurons have a more restricted innervation pattern and connect only a few glomeruli (Christensen, Waldrop, Harrow, \& Hildebrand, 1993). This type of interneuron seems predisposed to play a role in the coding of complex odor blends released by plants. Interestingly, patchy interneurons are present mainly in female M. sexta (Matsumoto \& Hildebrand, 1981). In the vinegar fly Drosophila melanogaster, patchy interneurons are responsible for non-linear processing of binary odor mixtures (Mohamed et al., 2019). For some glomeruli in D. melanogaster, this modulation occurred already at the presynaptic level, i.e. the level we monitored in our calcium imaging experiments. We also found indications of nonlinear processing in the antennal lobe of female M. sexta. The odor (Z)-3-hexenyl acetate, for example, elicited a strong antennal response, was present in 11 out of 17 plant samples tested, and, when tested on its own activates several glomeruli (Bisch-Knaden et al., 2018). However, two of the background plants although releasing this odor, and accordingly evoking a strong antennal response, did not elicit any activity in the antennal lobe. A similar inhibition of glomeruli in mixtures of odors was reported in a calcium imaging study in honey bees, where the inhibitory effect was stronger in ternary than in binary mixtures (Joerges, Kuttner, Galizia, $\&$ Menzel, 1997). As the plant bouquets tested in our study contained up to 20 EAD-active components, and as local interneurons in $M$. sexta, like in most insects, are mainly inhibitory (Christensen et al., 1993), the observed inhibitory mixture interactions after stimulation with blends of background plants seem plausible.

However, we also revealed coding characteristics that were similar at the periphery and in the brain, especially after stimulation with feeding-related odor bouquets. Representation of the essential nectar sources Datura and Agave flowers in the antennal lobe was outstanding, as none of the other plant bouquets elicited a higher response in any glomerulus than these two floral scents. Furthermore, the neural response of female $M$. sexta towards volatiles from its main nectar sources was not reduced following mating as it was reported for the noctuid moth Spodoptera littoralis (Saveer et al., 2012). Different life history traits of noctuid and sphingid moths might explain this different result: noctuid moths are generalists, and lay their eggs in clusters on a wide range of acceptable host plants. Sphingid moths like $M$. sexta, on the other hand, are usually specialized on a few host plant families and females lay only a few single eggs on a given plant. Thus, hawkmoths need to refill their energy reservoir between oviposition bouts at host plants that are rare in the habitat and therefore require long flights between them (Alarcon et al., 2008; Raguso, Henzel, et al., 2003). Moreover, female hawkmoths benefit from nectar feeding following mating as they live longer and produce more mature eggs compared to starved females (Sasaki \& Riddiford, 1984; von Arx, Sullivan, \& Raguso, 2013). The energy demand of hawkmoths is in addition especially high as both feeding and oviposition usually occur while the moth is hovering in front of the plant (Stockl \& Kelber, 2019). Taken together, the prominent and mating-status independent representation of floral bouquets at the antenna and in the antennal lobe of female $M$. sexta is in accordance with the moths' ecology.

440 While the coding of flower volatiles in nectar-feeding moths is probably independent of sex, odors indicating oviposition sites should be of special importance for female moths after mating. Two enlarged, female-specific glomeruli that are located at the entrance of the antennal nerve into the female antennal lobe - at the same position as the sex pheromone-processing macroglomerular complex in males (Matsumoto \& Hildebrand, 1981) — are suggested to be involved in oviposition choice (King, Christensen, \& Hildebrand, 2000). However, M. sexta's 
host plant bouquets did not activate these glomeruli (glomeruli 1 and 2, Table 2), confirming results of a study using vegetative headspace from the solanaceous hosts Datura, Nicotiana, and tomato. These odors failed to evoke a response in sensilla targeting the two female-specific glomeruli (Shields \& Hildebrand, 2000). Therefore, the intuitive hypothesis that these femalespecific glomeruli might be involved in the female-specific behavior of identifying an oviposition site seems unlikely. In contrast to the wide and strong activation of antennal lobe glomeruli by flower odors, $M$. sexta's host plant bouquets each activated only a single glomerulus. While the responding glomerulus towards Datura foliage was independent of the female's mating status, Proboscidea activated a different glomerulus in virgin than in mated females. This result is in line with the fact that the ecological meaning of Datura foliage does not change after mating as its smell indicates both a suitable host plant, and a profitable nectar source (Karpati et al., 2013). Proboscidea, on the other hand, does not provide nectar for hawkmoths, and is therefore interesting for the female moth only after mating. Many EAD-active compounds were tested in a previous calcium imaging study using monomolecular odorants as stimuli (Bisch-Knaden et al., 2018), allowing a comparison between these data and our imaging results obtained with natural mixtures. Some compounds present in the headspace of Proboscidea and Datura foliage, for example, when tested alone activated most strongly glomerulus 6 , a glomerulus that was not activated after stimulation with the complete headspaces, again indicating non-linear processing and robust presynaptic inhibitory interactions between glomeruli (Joerges et al., 1997; Mohamed et al., 2019). The two host-plant-activated glomeruli in mated females were as well responding to nectar sources and hosts of sympatric hawkmoths. However, host plants exclusively activated one of these glomeruli, whereas the other sources activated additional glomeruli. Therefore, the resulting neural representation of non-host plants in the antennal lobe of mated females was very different from the pattern evoked by host plants.

Interestingly, virgin and mated females differed markedly in their response to the odor of background plants: these plants activated only a small number of glomeruli (range: 0-9) in virgin females, and even less glomeruli (range: 0-2) in mated females. The few backgroundactivated glomeruli did not include the two host plant-activated glomeruli. The moths' reduced responses to background plants but not to host plants after mating, together with the finding that the host plant Proboscidea activates a different glomerulus in virgin and mated females, indicates that the olfactory system of $M$. sexta females becomes tuned towards host plants following mating. Mechanisms mediating these post-mating changes in moth olfactory processing seem to be independent of neurotransmitters like octopamine and serotonin (Barrozo et al., 2010) but might include neuropeptides as in the vinegar fly, Drosophila melanogaster (Hussain, Ucpunar, Zhang, Loschek, \& Kadow, 2016), and regulation of chemosensory-related genes like in Drosophila suzukii (Crava, Sassu, Tait, Becher, \& Anfora, 2019). Our data suggest that mated females could potentially be able to identify suitable oviposition sites by the relative activity of one or two glomeruli compared with the activity of other glomeruli. A similar sparse coding strategy was recently described for the discrimination of differentially attractive body odors by mosquitoes (Zhao et al., 2020). In this case, the relative activity of a single, humanodor-activated glomerulus versus a broadly tuned glomerulus has been proposed to enable the mosquito to identify its preferred human host.

As the single activated glomerulus was different after stimulation with the two host plant bouquets, which also did not share any EAD-active compounds, $M$. sexta females should be able to distinguish the two plants based on olfaction alone. Field observations and experiments show that females lay more eggs on Proboscidea than on solanaceous hosts, although the plants grow next to each other and have a similar leaf surface (Diamond \& Kingsolver, 2010; Mechaber \& Hildebrand, 2000). These findings indicate that M. sexta can indeed discriminate between host plants belonging to different plant families, although visual and tactile cues might play a role in combination with olfactory cues. The observed low overall activity across the 
antennal lobe evoked by host plant odors corresponds to the preference of $M$. sexta for plants with a faint smell when looking for oviposition sites. Inbred horse nettle (Solanum carolinense) exhibits much lower nocturnal volatile emissions than outbred horse nettle, a solanaceous host plant of M. sexta in the southeastern US. Correspondingly, female moths spend more time hovering near inbred plants, and lay more eggs there than on outbred plants. This preference is governed by olfactory cues alone as it persists in the absence of visual and contact cues (Kariyat et al., 2013). Furthermore, when given the choice between headspaces of two solanaceous host plant species with different total volatile concentration, $M$. sexta clearly prefers the weaker smelling plant. Diluting the headspace of the more intensely smelling plant leads to a reduction of this preference (Spaethe, Reinecke, Haverkamp, Hansson, \& Knaden, 2013). These findings show again that female moths consistently favor host plants with low volatile emission, probably because high emission of specific volatiles are signs of active plant defense mechanisms, indicating the presence of larval competitors (De Moraes et al., 2001), and leading to impaired larval growth (Delphia, De Moraes, Stephenson, \& Mescher, 2009). High levels of these herbivore-induced volatiles also attract predators and parasitoids (A. Kessler \& Baldwin, 2001; Turlings et al., 1995), and egg-laying moths therefore avoid these sites (De Moraes et al., 2001; Li, Garvey, Kaplan, Li, \& Carrillo, 2018). Conversely, when M. sexta has to choose between flowering tobacco plants from populations that differ in their flower volatile concentration, the moths clearly prefer to forage at flowers with a stronger smell (Haverkamp, Hansson, Baldwin, Knaden, \& Yon, 2018). Hence, M. sexta pursues different strategies when searching for oviposition or feeding sites, as the moths favor weakly or strongly scented sources, respectively.

In contrast to $M$. sexta's host plants, the bouquets of host plants of sympatric hawkmoths activated many glomeruli in virgins, and even more glomeruli in mated females. Two glomeruli contributed mostly to this effect as they were responding to all three non-host bouquets only after mating (glomeruli 12 and 13; Table 2). Odor-induced activation levels of these two glomeruli were positively correlated to odor-induced behavior in wind tunnel experiments using monomolecular odorants (Bisch-Knaden et al., 2018). However, only virgin females were included in this study, so conclusions regarding the behavior of mated females cannot be drawn. The strong activation of antennal lobe glomeruli by host plants of other hawkmoths living in the same habitat was in contrast to weak but specific activation of single glomeruli by host plants of $M$. sexta. The conspicuous activation patterns evoked by host plants of sympatric hawkmoths might serve as a stop signal for $M$. sexta during their search for a suitable oviposition site and therefore might help gravid females to avoid inappropriate hosts at a distance. It would be interesting to compare headspace-evoked activation patterns in the antennal lobe of co-occurring hawkmoths upon stimulation with odors of their own and of other species' host plants to test if this might be a general coding policy. Examples of olfaction-based avoidance of non-host plants was also reported for example in bark beetles (Huber, Gries, Borden, \& Pierce, 2000). Antennae of these insects respond strongly to many volatiles released by non-host trees. Like in the case of M. sexta, some compounds are present in the bouquet of both host and non-host plants, corroborating the hypothesis that odor-guided choice of host plants relies on blends of ubiquitous compounds in a specific ratio (Bruce \& Pickett, 2011), and concentration (Spaethe, Reinecke, Haverkamp, et al., 2013) rather than on the detection of hostexclusive odors.

541 By using ecologically relevant odors collected in the actual habitat of our model animal, $M$. sexta, we revealed olfactory coding strategies both for odors emanating from crucial resources but also for those emitted by substrates that should be avoided. We also show how the female mating status affects olfactory processing but, interestingly, in a way well adapted to the specific life history traits of the species under investigation. In a broader perspective, our study contributes to understanding innate neural representation of natural odor mixtures in the brain and coding strategies enabling animals to distinguish crucial resources from background noise. 


\section{Material und Methods}

\section{Headspace collection in the field}

We collected the headspace of plants in a habitat of Manduca sexta at the Santa Rita Experimental Range, $40 \mathrm{~km}$ south of Tucson, Arizona, at the foot of the Santa Rita Mountains $\left(31^{\circ} 78^{\prime} \mathrm{N}, 110^{\circ} 82^{\prime} \mathrm{W}\right)$. All plants species sampled (Table 1) are native to the habitat, and belong to the regular desert grassland vegetation at Santa Rita Experimental Range (Medina, 2003). At sunset, we carefully enclosed plants in polyethylene terephthalate bags (Toppits, Germany). Charcoal-filtered, environmental air was pumped into the bag through a silicone tube connected to a custom-made portable pump. Air was pumped out of the bag through a second silicone tube passing a volatile collection trap (Porapak-Q $25 \mathrm{mg}$, www.volatilecollectiontrap.com). Shortly after sunrise, we unpacked the plants, removed the volatile collection traps, and stored them at $-20^{\circ} \mathrm{C}$. We collected the headspaces of plants on

561

562

563

564

565

566

567

568

569

570

571

572

573

574

575

576

577

578

579

580

581

582

583

584

585

586

587

588 nine consecutive nights (August 19-27, 2018). In the first and the last night, we made a control collection with an empty bag placed on the ground close to the collection sites of plant headspaces. One volatile collection trap not used but treated in the same way as headspacecollecting traps served as a handling control. In Jena, Germany, all volatile collection traps were eluted with 4 x $100 \mu 1$ dichloromethane containing $5 \mathrm{ng} / \mu \mathrm{l}$ bromodecane as an internal standard. Chemical analysis

Headspace samples were analyzed by GC-MS (7890B GC System, 5977A MSD, Agilent Technologies, www.agilent.com) equipped with a polar column (HP-INNOWAX, $30 \mathrm{~m}$ long, $0.25 \mathrm{~mm}$ inner diameter, $25 \mu \mathrm{m}$ film thickness; Agilent) with helium as carrier gas. The inlet temperature was set to $240^{\circ} \mathrm{C}$. The temperature of the GC-oven was held at $40^{\circ} \mathrm{C}$ for $3 \mathrm{~min}$, and then increased by $10^{\circ} \mathrm{C}$ per min to $260^{\circ} \mathrm{C}$. This final temperature was held for $15 \mathrm{~min}$. The MS transferline was held at $260^{\circ} \mathrm{C}$, the MS source at $230^{\circ} \mathrm{C}$, and the MS quad at $150^{\circ} \mathrm{C}$. Mass spectra were taken in electron ionization mode $(70 \mathrm{eV})$ in the range from $\mathrm{m} / \mathrm{z} 29$ to 350 . GCMS data were processed with the MDS-ChemStation Enhanced Data Analysis software (Agilent).

\section{Breeding of Manduca sexta}

M. sexta larvae were reared in the laboratory on artificial diet (Grosse-Wilde et al., 2011). Female pupae were kept in a climate chamber $\left(25^{\circ} \mathrm{C}, 70 \%\right.$ relative humidity) with a reversed light cycle ( $8 \mathrm{hrs}$. dark/16 hrs. light), and moths were tested during their scotophase on day 2 to 4 after hatching (GC-EAD), or at day 3 after hatching (calcium imaging). Moths were unfed and had no experience with plant-derived volatiles. To obtain mated females, we placed them in a cage with an equal number of males one day before an experiment was planned. We checked the cage 3-4 hours later and removed all animals that were not mating.

\section{$G C$-EAD recordings}

We used GC with flame-ionization detection (GC-FID) coupled with electro-antennographic detection (EAD) to identify compounds in headspace collections that can be sensed by M. sexta. One antenna of a female moth (virgin and mated in equal numbers), age 2-4 days, was cut and connected to two glass-electrodes filled with physiological saline solution (Christensen \& Hildebrand, 1987). The reference electrode was inserted into the basal segment of the antenna, and the recording electrode was brought in contact with the tip of the antennae. The EAD signal (transferred via $\mathrm{Ag}-\mathrm{AgCl}$ wires) was pre-amplified (10x) with a probe connected to a highimpedance DC-amplifier (EAG-probe, Syntech, www.syntech.nl), and digitally converted (IDAC-4 USB, Syntech), visualized and recorded on a PC using the software Autospike (Syntech). For each run, $2 \mu \mathrm{l}$ of a headspace sample (a lower amount of $1 \mu \mathrm{l}$ for Agave flower and Datura flower) was injected into a GC-FID (6890N, Agilent) equipped with a polar column (HP-INNOWAX, $30 \mathrm{~m}$ long, $0.32 \mathrm{~mm}$ inner diameter, $0.25 \mu \mathrm{m}$ film thickness, Agilent) with helium as carrier gas. The inlet temperature was set to $250^{\circ} \mathrm{C}$. The temperature of the GC-oven was held at $40^{\circ} \mathrm{C}$ for $2 \mathrm{~min}$, and then increased by $10^{\circ} \mathrm{C}$ per min to $260^{\circ} \mathrm{C}$. This final temperature 
was held for $10 \mathrm{~min}$. The GC was equipped with an effluent splitter (Gerstel) at the end of the analytical column, with a GC:antenna split ratio of 1:10 and helium as carrier gas. One arm was connected with the FID of the GC, and the other arm entered a heated $\left(270^{\circ} \mathrm{C}\right)$ GC-EAD interface (Syntech) that was connected to a bent glass tube (diameter: $12 \mathrm{~mm}$ ). The antennadirected GC effluent was mixed with a humidified, charcoal-filtered air stream (11/min) to cool the effluent down, and guide it to the antenna. Signals from the moth's antenna and the FID were recorded simultaneously. Sample size was 4-7 antenna per sample type; if a given sample type did not elicit a single response in three different animals, it was not tested any further (Argemone, Gutierrezia, empty bag). A GC-peak was scored as EAD-active if it induced a response at the same retention time in at least three antennae, and if this GC-fraction was present in at least one other headspace of the same type.

Identification of compounds

611 On both GC-instruments (GC-MS and GC-FID) we ran a series of 20 n-alkanes, and matched retention times of EAD-active peaks and peaks obtained with the GC-MS using their Kovats retention indices. EAD-active peaks were tentatively identified by comparison of their mass spectra and Kovats retention indices with those from a reference library (National Institute of Standards and Technologies), and a database built in our laboratory with synthetic standards using the same GC-MS instrument. Compounds yielding a match of mass spectra above $90 \%$ were rated as tentatively identified. The fragmentation pattern of some EAD-active peaks could not be clearly matched to any library compound, and were labeled as unidentified (see Fig. 2C). Preparation for calcium imaging experiments

Female moths were tested; they were either virgin, or mated on day 1 after emergence. On day 2 , moths were positioned in a $15-\mathrm{ml}$ plastic tube with the tip cut open. The head was protruding at the narrow end and was fixed in this position with dental wax. Labial palps and proboscis were also fixed with wax to reduce movement artifacts during the experiments. A window was cut in the head capsule between the compound eyes, and the tissue covering the brain was removed until the antennal lobes were visible. We added $50 \mu$ I Pluronic F-127 (Invitrogen) to $1 \mathrm{mg}$ of the membrane-permeant form of a fluorescent calcium indicator (Calcium Green-1 AM, Invitrogen), and sonicated the solution for $10 \mathrm{~min}$. Then, we added $800 \mu \mathrm{l}$ physiological saline solution (Christensen \& Hildebrand, 1987), and sonicated again for $10 \mathrm{~min}$. Twenty $\mu 1$ of this dye solution was applied to the exposed brain, and the preparation was incubated in a humid chamber for $45 \mathrm{~min}$ at room temperature. Then, we rinsed the brain several times with physiological saline solution to remove excess dye, and stored the moths at $4^{\circ} \mathrm{C}$ overnight to calm them down and reduce their movements. Imaging experiments were performed the following day (day 3 after emergence).

\section{Calcium imaging}

The imaging setup consisted of a CCD camera (Olympus U-CMAD3) mounted to an upright microscope (Olympus BX51WI) equipped with a water immersion objective (Olympus, 10x/0.30). Calcium green-1 AM was excited at $475 \mathrm{~nm}$ (500 nm shortpass optical filter; xenon arc lamp, Polychrome V, Till Photonics), and fluorescence was detected at 490/515 nm (dichroic longpass/longpass). The set-up was controlled by the software Tillvision version 4.6 (Till Photonics). Four-fold symmetrical binning resulted in image sizes of 344 x 260 pixels, with one pixel corresponding to an area of $4 \mu \mathrm{m} \times 4 \mu \mathrm{m}$.

\section{Odor stimulation}

To create a functional map of glomeruli in the antennal lobe, we first tested 19 diagnostic odors (Bisch-Knaden et al., 2018) in each animal. Then, we tested 17 headspaces of plants (Table 1), and one collection with an empty bag. The same samples as in GC-EAD experiments were used. Ten $\mu$ l of a diagnostic odor or an eluted headspace were applied onto a circular piece of filter paper (diameter: $12 \mathrm{~mm}$, Whatman) that was inserted in a glass pipette; $10 \mu \mathrm{l}$ of the solvent mineral oil (diagnostic odors) or the eluent dichloromethane (headspace) served as control stimuli. A pipet tip sealed with dental wax closed the pipettes until the start of the experiment. 
650 As dichloromethane alone evoked a response in the antennal lobe (Fig. 3B), pipettes with 651 headspace samples and two pipettes with dichloromethane were left open for 3-5 min before 652 sealing them to allow evaporation of the eluent. Filter papers were renewed every experimental day (diagnostic odors), or the pipettes were stored at $-20^{\circ} \mathrm{C}$, and used on up to three experimental days (headspace). The immobilized moth was placed upright under the microscope. A glass tube (diameter: $5 \mathrm{~mm}$ ) was directed perpendicular to one antenna, and delivered a constant stream of charcoal-filtered, moistened air $(0.51 / \mathrm{min})$. Two glass pipettes were inserted through small holes in the tube. One pipette (inserted $5.5 \mathrm{~cm}$ from end of tube) was empty and added clean air to the continuous airstream $(0.51 / \mathrm{min})$. This airstream could automatically be switched (Syntech Stimulus Controller CS-55) to the second pipette (inserted $3.5 \mathrm{~cm}$ from the end of tube) that contained an odor-laden filter paper. By this procedure, the airstream reaching the antenna was not altered during odor stimulation, thus reducing mechanical disturbances. One odor stimulation experiment lasted $10 \mathrm{~s}$ and was recorded with a sampling rate of $4 \mathrm{~Hz}$ corresponding to 40 frames. The time course of an odorant stimulation experiment was as follows: 2-s clean airstream (frame 1-8), 2-s odorous airstream (frame 916), and 6-s clean airstream (frame 17-40). Odors were presented with at least 1-min interstimulus interval to avoid adaptation. The sequence of headspace stimulations changed from animal to animal, and a control stimulus with dichloromethane was presented at the beginning and at the end of this sequence.

\section{Processing of calcium imaging data}

670 Stimulation experiments resulted in a series of 40 consecutive frames that were analyzed with custom written software (IDL, ITT Visual Informations Solutions). Several processing steps were applied to enhance the signal-to-noise ratio: (1) background correction: background activity was defined as the average fluorescence $(\mathrm{F})$ of frames 3-7 (i.e., before stimulus onset) and was subtracted from the fluorescence of each frame. This background-corrected value (deltaF) was divided by the background fluorescence to get the relative changes of fluorescence over background fluorescence for each frame (deltaF/F). (2) Bleaching correction: the fluorescent bleached slowly during the exposure to light, and therefore, we subtracted from each frame an exponential decay curve that was estimated from the bleaching course of frame 3-7 and frame 26-40 (i.e., before and after stimulus and response). (3) Median filtering: a spatial median filter with a width of 7 pixels was applied to remove outliers. (4) Movement correction: possible shifts of the antennal lobe from one stimulation experiment to the next one were corrected by aligning frame 20 of each experiment to frame 20 of the median experiment in a given animal. The outline of the antennal lobe and remains of tracheae served as guides for this movement correction procedure. Increased neural activity, indicated as an increase of the intracellular calcium concentration after stimulation with the diagnostic odors, was leading to spatially restricted spots of increased fluorescence in the antennal lobe. In the center of each activity spot, the average deltaF/F was recorded in an area of the size of a small to mediumsized glomerulus $(60 \mu \mathrm{m} \times 60 \mu \mathrm{m})$. Time traces of deltaF/F were averaged over three successive frames for each activity spot. In these smoothed time traces, the maximum deltaF/F after stimulus onset was determined. The average of the maximum value and the value before and after the maximum was calculated and was defined as the response of the animal to the odor stimulation at the given activity spot.

\section{Analysis of response to headspace stimulation}

Activation patterns evoked by the diagnostic odors helped to establish an individual schematic of 23 putative glomeruli for each animal (Fig. 3). Then, responses in these 23 glomeruli were calculated for stimulations with headspaces and dichloromethane. To identify headspaceactivated glomeruli, we tested for each glomerulus if its mean response towards the two control stimulations with dichloromethane was clearly different from the response to the headspaces ( $p<0.01$, Friedman test with Dunn's multiple comparisons test). We then normalized responses 700 for each glomerulus in a given animal according to its response to headspaces and 
dichloromethane (lowest response $=0$, highest response $=100$ ) to balance for variability between individuals.

\section{Statistical analysis}

Sample sizes and statistical tests used are given in the text and in figure legends. Statistical tests were performed with PAST (version 3.26, http://folk.uio.no/ohammer/past/), and GraphPad InStat (version 3.10, GraphPad Software, San Diego California USA, www.graphpad.com).

Source data S1. XCMS analysis of 69 headspaces.

Source data S2. GC-EAD results from 80 antennae.

Source data S3. Calcium imaging results from 10 virgin and 10 mated females.

\section{Acknowledgments}

We thank Brett C. Blum and Mark E. Heitlinger for kindly hosting us at the Santa Rita Experimental Range, Sascha Bucks for breeding M. sexta, Kerstin Weniger for help with chemical analyses, Mohammed Khallaf Ali for introducing us to XCMS, and Daniel Veit for building equipment for mobile headspace collection.

Funding: Max-Planck Society (all authors), CSIRO Health and Biosecurity Acorn Grant (MAR).

\section{References:}

Alarcon, R., Davidowitz, G., \& Bronstein, J. L. (2008). Nectar usage in a southern Arizona hawkmoth community. Ecological Entomology, 33(4), 503-509. doi:10.1111/j.13652311.2008.00996.x

Barrozo, R. B., Jarriault, D., Simeone, X., Gaertner, C., Gadenne, C., \& Anton, S. (2010). Mating-induced transient inhibition of responses to sex pheromone in a male moth is not mediated by octopamine or serotonin. Journal of Experimental Biology, 213(7), 1100-1106. doi:10.1242/jeb.040139

Bisch-Knaden, S., Dahake, A., Sachse, S., Knaden, M., \& Hansson, B. S. (2018). Spatial representation of feeding and oviposition odors in the brain of a hawkmoth. Cell Reports, 22(9), 2482-2492. doi:10.1016/j.celrep.2018.01.082

Bruce, T. J. A., \& Pickett, J. A. (2011). Perception of plant volatile blends by herbivorous insects - finding the right mix. Phytochemistry, 72(13), 1605-1611. doi:10.1016/j.phytochem.2011.04.011

Bruce, T. J. A., Wadhams, L. J., \& Woodcock, C. M. (2005). Insect host location: a volatile situation. Trends in Plant Science, 10(6), 269-274. doi:10.1016/j.tplants.2005.04.003

Burger, H., Marquardt, M., Babucke, K., Heuel, K. C., Ayasse, M., Dotterl, S., \& Galizia, C. G. (2021). Neural and behavioural responses of the pollen-specialist bee Andrena vaga to Salix odours. Journal of Experimental Biology, 224(13). doi:10.1242/jeb.242166

Cha, D. H., Nojima, S., Hesler, S. P., Zhang, A., Linn, C. E., Roelofs, W. L., \& Loeb, G. M. (2008). Identification and field evaluation of grape shoot volatiles attractive to female grape berry moth (Paralobesia viteana). Journal of Chemical Ecology, 34(9), 1180-1189. doi:10.1007/s10886-008-9517-0

Christensen, T. A., \& Hildebrand, J. G. (1987). Male-specific, sex pheromone-selective projection neurons in the antennal lobes of the moth Manduca sexta. Journal of Comparative Physiology A, 160(5), 553-569.

Christensen, T. A., Waldrop, B. R., Harrow, I. D., \& Hildebrand, J. G. (1993). Local interneurons and information-processing in the olfactory glomeruli of the moth 
Manduca sexta. Journal of Comparative Physiology a-Sensory Neural and Behavioral Physiology, 173(4), 385-399.

Conchou, L., Anderson, P., \& Birgersson, G. (2017). Host plant species differentiation in a polyphagous moth: olfaction is enough. Journal of Chemical Ecology, 43(8), 794-805. doi:10.1007/s10886-017-0876-2

Crava, C. M., Sassu, F., Tait, G., Becher, P. G., \& Anfora, G. (2019). Functional transcriptome analyses of Drosophila suzukii antennae reveal mating-dependent olfaction plasticity in females. Insect Biochemistry and Molecular Biology, 105, 51-59. doi:10.1016/j.ibmb.2018.12.012

De Moraes, C. M., Mescher, M. C., \& Tumlinson, J. H. (2001). Caterpillar-induced nocturnal plant volatiles repel conspecific females. Nature, 410(6828), 577-580. doi:10.1038/35069058

Delphia, C. M., De Moraes, C. M., Stephenson, A. G., \& Mescher, M. C. (2009). Inbreeding in horsenettle influences herbivore resistance. Ecological Entomology, 34(4), 513-519. doi:10.1111/j.1365-2311.2009.01097.x

Diamond, S. E., \& Kingsolver, J. G. (2010). Fitness consequences of host plant choice: a field experiment. Oikos, 119(3), 542-550. doi:10.1111/j.1600-0706.2009.17242.x

Emiliano Trejo-Salazar, R., Scheinvar, E., \& Eguiarte, L. E. (2015). Who really pollinates agaves? Diversity of floral visitors in three species of Agave (Agavoideae: Asparagaceae). Revista Mexicana de Biodiversidad, 86(2), 358-369.

Fandino, R. A., Haverkamp, A., Bisch-Knaden, S., Zhang, J., Bucks, S., Nguyen, T. A. T., . . . Grosse-Wilde, E. (2019). Mutagenesis of odorant coreceptor Orco fully disrupts foraging but not oviposition behaviors in the hawkmoth Manduca sexta. Proceedings of the National Academy of Sciences of the United States of America, 116(31), 1567715685. doi:10.1073/pnas.1902089116

Fraser, A. M., Mechaber, W. L., \& Hildebrand, J. G. (2003). Electroantennographic and behavioral responses of the sphinx moth Manduca sexta to host plant headspace volatiles. Journal of Chemical Ecology, 29(8), 1813-1833.

Gadenne, C., Barrozo, R. B., \& Anton, S. (2016). Plasticity in insect olfaction: to smell or not to smell? In M. R. Berenbaum (Ed.), Annual Review of Entomology, Vol 61 (Vol. 61, pp. 317-333).

Grant, V., \& Grant, K. A. (1983). Hawkmoth pollination of Mirabilis longiflora (Nyctaginaceae). Proceedings of the National Academy of Sciences, 80, 1298-1299.

Grosse-Wilde, E., Kuebler, L. S., Bucks, S., Vogel, H., Wicher, D., \& Hansson, B. S. (2011). Antennal transcriptome of Manduca sexta. Proceedings of the National Academy of Sciences of the United States of America, 108(18), 7449-7454. doi:10.1073/pnas.1017963108

Hansson, B. S., Carlsson, M. A., \& Kalinova, B. (2003). Olfactory activation patterns in the antennal lobe of the sphinx moth, Manduca sexta. Journal of Comparative Physiology A, 189(4), 301-308. doi:10.1007/s00359-003-0403-5

Hare, J. D., \& Sun, J. J. (2011). Production of induced volatiles by Datura wrightii in response to damage by insects: effect of herbivore species and time. Journal of Chemical Ecology, 37(7), 751-764. doi:10.1007/s10886-011-9985-5

Haverkamp, A., Hansson, B. S., Baldwin, I. T., Knaden, M., \& Yon, F. (2018). Floral trait variations among wild tobacco populations influence the foraging behavior of hawkmoth pollinators. Frontiers in Ecology and Evolution, 28. doi:https://doi.org/10.3389/fevo.2018.00019 
803

804

805

806

807

808

809

810

811

812

813

814

815

816

817

818

819

820

821

822

823

824

825

826

827

828

829

830

831

832

833

834

835

836

837

838

839

840

841

842

He, J., Halitschke, R., Schuman, M. C., \& Baldwin, I. T. (2021). Light dominates the diurnal emissions of herbivore-induced volatiles in wild tobacco. BMC Plant Biology, 21(1). doi:10.1186/s12870-021-03179-z

Hoballah, M. E., Stuurman, J., Turlings, T. C. J., Guerin, P. M., Connetable, S., \& Kuhlemeier, C. (2005). The composition and timing of flower odour emission by wild Petunia axillaris coincide with the antennal perception and nocturnal activity of the pollinator Manduca sexta. Planta, 222(1), 141-150. doi:10.1007/s00425-005-1506-8

Holopainen, J. K., \& Gershenzon, J. (2010). Multiple stress factors and the emission of plant VOCs. Trends in Plant Science, 15(3), 176-184. doi:10.1016/j.tplants.2010.01.006

Homberg, U., Montague, R. A., \& Hildebrand, J. G. (1988). Anatomy of antenno-cerebral pathways in the brain of the sphinx moth Manduca sexta. Cell and Tissue Research, 254(2), 255-281.

Honda, K., Omura, H., \& Hayashi, N. (1998). Identification of floral volatiles from Ligustrum japonicum that stimulate flower-visiting by cabbage butterfly, Pieris rapae. Journal of Chemical Ecology, 24(12), 2167-2180. doi:10.1023/a:1020750029362

Huber, D. P. W., Gries, R., Borden, J. H., \& Pierce, H. D. (2000). A survey of antennal responses by five species of coniferophagous bark beetles (Coleoptera: Scolytidae) to bark volatiles of six species of angiosperm trees. Chemoecology, 10(3), 103-113. doi:10.1007/pl00001811

Hussain, A., Ucpunar, H. K., Zhang, M., Loschek, L. F., \& Kadow, I. C. G. (2016). Neuropeptides modulate female chemosensory processing upon mating in Drosophila. PLoS Biology, 14(5). doi:10.1371/journal.pbio.1002455

Joerges, J., Kuttner, A., Galizia, C. G., \& Menzel, R. (1997). Representations of odours and odour mixtures visualized in the honeybee brain. Nature, 387(6630), 285-288.

Kariyat, R. R., Mauck, K. E., Balogh, C. M., Stephenson, A. G., Mescher, M. C., \& De Moraes, C. M. (2013). Inbreeding in horsenettle (Solanum carolinense) alters night-time volatile emissions that guide oviposition by Manduca sexta moths. Proceedings of the Royal Society B-Biological Sciences, 280(1757). doi:10.1098/rspb.2013.0020

Karpati, Z., Knaden, M., Reinecke, A., \& Hansson, B. S. (2013). Intraspecific combinations of flower and leaf volatiles act together in attracting hawkmoth pollinators. PLOS ONE, 8(9). doi:10.1371/journal.pone.0072805

Kessler, A., \& Baldwin, I. T. (2001). Defensive function of herbivore-induced plant volatile emissions in nature. Science, 291(5511), 2141-2144.

Kessler, D., Gase, K., \& Baldwin, I. T. (2008). Field experiments with transformed plants reveal the sense of floral scents. Science, 321(5893), 1200-1202. doi:10.1126/science.1160072

Kigathi, R. N., Weisser, W. W., Reichelt, M., Gershenzon, J., \& Unsicker, S. B. (2019). Plant volatile emission depends on the species composition of the neighboring plant community. BMC Plant Biology, 19. doi:10.1186/s12870-018-1541-9

King, J. R., Christensen, T. A., \& Hildebrand, J. G. (2000). Response characteristics of an identified, sexually dimorphic olfactory glomerulus. Journal of Neuroscience, 20(6), 2391-2399.

Knudsen, J. T., Eriksson, R., Gershenzon, J., \& Stahl, B. (2006). Diversity and distribution of floral scent. Botanical Review, 72(1), 1-120. doi:10.1663/00068101(2006)72[1:dadofs]2.0.co;2

Lahondere, C., Vinauger, C., Okubo, R. P., Wolff, G. H., Chan, J. K., Akbari, O. S., \& Riffell, J. A. (2020). The olfactory basis of orchid pollination by mosquitoes. Proceedings of the 
National Academy of Sciences of the United States of America, 117(1), 708-716. doi:10.1073/pnas.1910589117

Li, X. H., Garvey, M., Kaplan, I., Li, B. P., \& Carrillo, J. (2018). Domestication of tomato has reduced the attraction of herbivore natural enemies to pest-damaged plants. Agricultural and Forest Entomology, 20(3), 390-401. doi:10.1111/afe.12271

Liu, X. L., Zhang, J., Yan, Q., Miao, C. L., Han, W. K., Hou, W., ... Knaden, M. (2020). The molecular basis of host selection in a crucifer-specialized moth. Current Biology, 30(22), 4476-+. doi:10.1016/j.cub.2020.08.047

Matsumoto, S. G., \& Hildebrand, J. G. (1981). Olfactory mechanisms in the moth Manduca sexta: response characteristics and morphology of central neurons in the antennal lobes. Proceedings of the Royal Society Series B-Biological Sciences, 213(1192), 249-+. doi:10.1098/rspb.1981.0066

Mechaber, W. L., Capaldo, C. T., \& Hildebrand, J. G. (2002). Behavioral responses of adult female tobacco hornworms, Manduca sexta, to hostplant volatiles change with age and mating status. Journal of Insect Science, 2(5), 1-8.

Mechaber, W. L., \& Hildebrand, J. G. (2000). Novel, non-solanaceous hostplant record for Manduca sexta (Lepidoptera: Sphingidae) in the southwestern United States. Annals of the Entomological Society of America, 93(3), 447-451. doi:10.1603/00138746(2000)093[0447:nnshrf]2.0.co;2

Medina, A. L. (2003). Historical and recent flora of the Santa Rita Experimental Range. USDA Forest Service Proceedings, RMRS-P-30, 141-148.

Mohamed, A. A. M., Retzke, T., Das Chakraborty, S., Fabian, B., Hansson, B. S., Knaden, M., \& Sachse, S. (2019). Odor mixtures of opposing valence unveil inter-glomerular crosstalk in the Drosophila antennal lobe. Nature Communications, 10. doi:10.1038/s41467-019-09069-1

Mumm, R., \& Dicke, M. (2010). Variation in natural plant products and the attraction of bodyguards involved in indirect plant defense. Canadian Journal of Zoology, 88(7), 628-667. doi:10.1139/z10-032

Oland, L. A., \& Tolbert, L. P. (1988). Effects of hydroxyurea parallel the effects of radiation in developing olfactory glomeruli in insects. Journal of Comparative Neurology, 278(3), 377-387. doi:10.1002/cne.902780307

Paré, P. W., \& Tumlinson, J. H. (1999). Plant volatiles as a defense against insect herbivores. Plant Physiology, 121(2), 325-331. doi:10.1104/pp.121.2.325

Raguso, R. A., Henzel, C., Buchmann, S. L., \& Nabhan, G. P. (2003). Trumpet flowers of the Sonoran Desert: floral biology of Peniocereus cacti and Sacred Datura. International Journal of Plant Sciences, 164(6), 877-892. doi:10.1086/378539

Raguso, R. A., Levin, R. A., Foose, S. E., Holmberg, M. W., \& McDade, L. A. (2003). Fragrance chemistry, nocturnal rhythms and pollination "syndromes" in Nicotiana. Phytochemistry, 63(3), 265-284. doi:10.1016/s0031-9422(03)00113-4

Reisenman, C. E., Dacks, A. M., \& Hildebrand, J. G. (2011). Local interneuron diversity in the primary olfactory center of the moth Manduca sexta. Journal of Comparative Physiology A, 197(6), 653-665. doi:10.1007/s00359-011-0625-x

Riffell, J. A., Lei, H., Abrell, L., \& Hildebrand, J. G. (2013). Neural basis of a pollinator's buffet: olfactory specialization and learning in Manduca sexta. Science, 339(6116), 200-204. doi:10.1126/science.1225483

Sachse, S., Rappert, A., \& Galizia, C. G. (1999). The spatial representation of chemical structures in the antennal lobe of honeybees: steps towards the olfactory code. European Journal of Neuroscience, 11(11), 3970-3982. 
891

892

893

894

895

896

897

898

899

900

901

902

903

904

905

906

907

908

909

910

911

912

913

914

915

916

917

918

919

920

921

922

923

924

925

926

927

928

929

930

931

932

933

934

935

936

937

938

Sasaki, M., \& Riddiford, L. M. (1984). Regulation of reproductive behavior and egg maturation in the tobacco hawk moth, Manduca sexta. Physiological Entomology, 9(3), 315-327. doi:10.1111/j.1365-3032.1984.tb00713.x

Saveer, A. M., Kromann, S. H., Birgersson, G., Bengtsson, M., Lindblom, T., Balkenius, A., ... Ignell, R. (2012). Floral to green: mating switches moth olfactory coding and preference. Proceedings of the Royal Society B-Biological Sciences, 279(1737), 23142322. doi:10.1098/rspb.2011.2710

Schubert, M., Hansson, B. S., \& Sachse, S. (2014). The banana code: natural blend processing in the olfactory circuitry of Drosophila melanogaster. Frontiers in Physiology, 5. doi:10.3389/fphys.2014.00059

Shields, V. D. C., \& Hildebrand, J. G. (2000). Responses of a population of antennal olfactory receptor cells in the female moth Manduca sexta to plant-associated volatile organic compounds. Journal of Comparative Physiology A, 186(12), 1135-1151.

Spaethe, A., Reinecke, A., Haverkamp, A., Hansson, B. S., \& Knaden, M. (2013). Host plant odors represent immiscible information entities - blend composition and concentration matter in hawkmoths. PLOS ONE, 8(10), e77135. doi:10.1371/journal.pone.0077135

Spaethe, A., Reinecke, A., Olsson, S. B., Kesavan, S., Knaden, M., \& Hansson, B. S. (2013). Plant species- and status-specific odorant blends guide oviposition choice in the moth Manduca sexta. Chemical Senses, 38(2), 147-159.

Stockl, A. L., \& Kelber, A. (2019). Fuelling on the wing: sensory ecology of hawkmoth foraging. Journal of Comparative Physiology a-Neuroethology Sensory Neural and Behavioral Physiology, 205(3), 399-413. doi:10.1007/s00359-019-01328-2

Suckling, D. M., Karg, G., Gibb, A. R., \& Bradley, S. J. (1996). Electroantennogram and oviposition responses of Epiphyas postvittana (Lepidoptera: Tortricidae) to plant volatiles. New Zealand Journal of Crop and Horticultural Science, 24(4), 323-333.

Tasin, M., Backman, A. C., Anfora, G., Carlin, S., loriatti, C., \& Witzgall, P. (2010). Attraction of female grapevine moth to common and specific olfactory cues from 2 host plants. Chemical Senses, 35(1), 57-64. doi:10.1093/chemse/bjp082

Tautenhahn, R., Patti, G. J., Rinehart, D., \& Siuzdak, G. (2012). XCMS Online: a web-based platform to process untargeted metabolomic data. Analytical Chemistry, 84(11), 5035-5039. doi:10.1021/ac300698c

Torretta, J. P., Navarro, F., \& Medan, D. (2009). Nocturnal floral visitors of sunflower (Helianthus annuus, Asterales: Asteraceae) in Argentina. Revista de la Sociedad Entomologica Argentina, 68(3-4), 339-350.

Turlings, T. C. J., Loughrin, J. H., McCall, P. J., Rose, U. S. R., Lewis, W. J., \& Tumlinson, J. H. (1995). How caterpillar-damaged plants protect themselves by attracting parasitic wasps. Proceedings of the National Academy of Sciences of the United States of America, 92(10), 4169-4174. doi:10.1073/pnas.92.10.4169

Visser, J. H., \& Ave, D. A. (1978). General green leaf volatiles int he olfactory orientation of the colorado beetle, Leptinotarsa decemlineata. Entomologia Experimentalis et Applicata, 24(3), 738-749. doi:10.1111/j.1570-7458.1978.tb02838.x

von Arx, M., Sullivan, K. A., \& Raguso, R. A. (2013). Dual fitness benefits of post-mating sugar meals for female hawkmoths (Hyles lineata). Journal of Insect Physiology, 59(4), 458465. doi:10.1016/j.jinsphys.2013.01.006

Webster, B., Bruce, T., Pickett, J., \& Hardie, J. (2010). Volatiles functioning as host cues in a blend become nonhost cues when presented alone to the black bean aphid. Animal Behaviour, 79(2), 451-457. doi:10.1016/j.anbehav.2009.11.028 
Webster, B., \& Carde, R. T. (2017). Use of habitat odour by host-seeking insects. Biological Reviews, 92(2), 1241-1249. doi:10.1111/brv.12281

Zhang, J., Raza, S. A. K., Wei, Z., Keesey, I. W., Parker, A. L., Feistel, F., . . Hansson, B. S. (2022). Competing beetles attract egg laying in a hawkmoth. Current Biology. doi:https://doi.org/10.1016/i.cub.2021.12.021

Zhao, Z., Zung, J. L., Kriete, A. L., Iqbal, A., Younger, M. A., Matthews, B. J., . . McBride, C. S.

Zhu, Y. C., Keaster, A. J., \& Gerhardt, K. O. (1993). Field observations on attractiveness of (2020). Chemical signatures of human odour generate a unique neural code in the brain of Aedes aegypti mosquitoes bioRxiv. selected blooming plants to noctuid moths and electroantennogram responses of Entomology, 22(1), 162-166. doi:10.1093/ee/22.1.162 